\title{
DERIVATION OF CRITERIA FOR ASSESSING SOLUTION PRINCIPLES CONFORMAL FOR ADDITIVE MANUFACTURING
}

\author{
Tüzün, Gregory-Jamie; \\ Garrelts, Enno; \\ Roth, Daniel; \\ Binz, Hansgeorg \\ University of Stuttgart
}

\begin{abstract}
Additively manufactured final products and components are not always tailored to the additive manufacturing (AM) process, but they need to be in order to exploit the many advantages and potentials that AM provides. Therefore, an appropriate AM design should be targeted, which reduces the necessary iterations in the developing process of AM products. Although there is a large number of existing literature on the Design for Additive Manufacturing (DfAM), designers usually lack criteria in order to assess AM-conformity in conceptual design. In this paper, we provide a basis for the assessment of solution principles regarding their conformity for additive manufacturing.

First, existing literature on DfAM and AM products is reviewed comprehensively to derive criteria for the AM-conformity of solution principles. Subsequently, the correlations between these criteria are identified including the interdependencies to be considered when assessing AM-conformity. A basis for assessment is created, which offers designers early support in the development of AM-conformal designs.
\end{abstract}

Keywords: Additive Manufacturing, Design for Additive Manufacturing (DfAM), Conceptual design, Solution principles, Conformal Additive Manufacturing

\section{Contact:}

Tüzün, Gregory-Jamie

University of Stuttgart

Institute for Engineering Design and Industrial Design

Germany

gregory-jamie.tuezuen@iktd.uni-stuttgart.de 


\section{INTRODUCTION}

Additive manufacturing (AM) describes manufacturing processes in which components are built up layer by layer through successive addition of material (Gebhardt, 2012). Over the past 30 years, the application scope of additive manufacturing has changed from prototypes to final production (Thompson et al., 2016). Particularly the three additive manufacturing processes fused deposition modeling (FDM), selective laser melting (SLM) and selective laser sintering (SLS) are used to produce final products (Leutenecker-Twelsiek et al., 2016).

The consideration of an additive manufacturing suitable selection, development and design of products is focused on several publications (Klahn et al., 2014; Laverne et al., 2014; Kumke et al., 2016). An AM-conformal design exceeds a simply suitable design for AM. The term "AM-conformal" is based on the Design for Manufacturing (DfM) and refers to designing specifically for the additive manufacturing process to minimize costs and counteract manufacturing problems (Rosen, 2007; Kumke, 2018). In order to methodically support AM-conformal design, the Design for Additive Manufacturing (DfAM) was established which is based on DfM (Rosen, 2007) and focuses on easing the manufacturability of additively manufactured components. As a general term, DfAM includes design criteria that consider the characteristics and restrictions of additive manufacturing. On this basis, DfAM provides applicable methods and tools for use in the various development phases (Laverne et al., 2015; Yang and Zhao, 2015). For instance, Medellin-Castillo and Zaragoza-Siqueiros (2019) established DfAM design and manufacturing strategies to ensure the manufacturability of components using FDM, thus ensuring an AM-conformal design of final components. In addition, Kumke et al. (2016) present a methodological framework of DfAM to develop AM-conformal components. It addresses the assessment of the technical and economic feasibility of a designed AM component. In conceptual design, DfAM methods are required (Pradel et al., 2018). Studies on the application of DfAM implies that the AM-conformal design of final components should already be considered in the concept phase (Posser and Oliveira, 2020), where it has the greatest impact on AM-conformity (Valjak and Bojčetić, 2019). This can be achieved, for example, by early definition of the part orientation (Klahn et al., 2016). However, in the early concept phase only the solution principles underlying the component are available (Pahl et al., 2007), so that the AM-conformity of these solution principles should be ensured.

Watschke et al. (2019) describe recommendations and restrictions for a conformal AM design with respect to only a few selected solution principles, but do not define any generally applicable criteria. On the contrary, Weiss (2019) established criteria for assessing the AM-conformity of solution principles, although these were derived from his own experience and are not described in detail. Booth et al. (2017) provide a first worksheet for evaluating the manufacturability of an AM component. However, this is aimed at inexperienced users and provides only a few evaluation criteria for assessing AM-conformity. Accordingly, there is a need for applicable and extensive criteria for assessing the AM-conformity of solution principles in conceptual design.

\section{PROBLEM CLARIFICATION AND GOAL}

A solution principle is the fundamental implementation of a function and therefore utilizes chemical or physical effects (VDI 2221:1993). Accordingly, a solution principle describes a functional solution and includes design principles rather than a detailed design to which design guidelines apply (Watschke, 2019). Particularly in AM, one focus is to consolidate parts by integrating functions of components into one part, thereby combining the underlying solution principles. Although, solution principles are considered as process-independent (Leutenecker-Twelsiek, 2019), the assessment of their AM-conformity does not seem conceivable at first. Only by describing their geometrical, structural, and material properties it is possible to examine the AM-conformity. Hence, this paper focuses on the assessment of already developed solution principles. Previous researchers evaluate AM-conformity based on already manufactured parts (e.g. Booth et al., 2017). However, the level of detail in parts is higher than for solution principles, which is why current assessment criteria for solution principles can only be adapted to a limited extent. Despite design guidelines, there is a lack of comprehensive criteria that are tailored to solution principles and assist the designers in their decision-making whether a solution principle is AM-conformal or not. Consequently, a basis shall be developed appropriate for assessing the AM-conformity of solution principles and as support in conceptual design. Furthermore, the interdependencies of the criteria to be considered in the assessment shall be presented. 


\section{METHODOLOGY}

The methodological framework of this paper is based on the Design Research Methodology (DRM) of Blessing and Chakrabarti (2009). Sections 1 to 3 comprise the first step of the DRM procedure and highlight the current state of research. A systematic literature review will be carried out in Section 4 following the Descriptive Study I. The procedure will be described in detail and aims to find recommendations and restrictions on AM-conformity.

Afterwards, within the Prescriptive Study in Section 5, criteria for the AM-conformity of solution principles are derived, which provides the fundamentals for assessing the conformity. The criteria and their interdependencies will be briefly discussed to answer the following research question: According to the present state of research, which criteria should be used to assess the AM-conformity of solution principles? Finally, our work will be summarized to point out further research potential.

\section{CRITERIA FOR AM-CONFORMITY OF SOLUTION PRINCIPLES - A SYSTEMATIC LITERATURE REVIEW}

A systematic literature review was conducted to identify recommendations and restrictions for AM-conformal design from a literature perspective. Thus, existing methods and tools as well as components and products were examined, which were developed in the context of DfAM. On this basis, conclusions could be drawn about the AM-conformity of solution principles. The procedure can be divided into the following four steps:

1. Establishing four search strategies based on previously identified keywords.

2. Research in four indexed, electronic literature databases with the combined keywords.

3. Initial selection of the found papers.

4. Detailed analysis of relevant papers.

We summarized the results below to maintain an appropriate framework for the paper. In order to structure the research, keywords were first formed. For each keyword, synonyms and alternative terms were obtained from significant literature (see Table 1). One synonym of each keyword was then combined to research for:

- $\quad$ process-dependent AM-conformity via the keywords "process" and "AM-conformity" (S1),

- general criteria on AM-conformity via the keywords "AM-conformity" and "criteria" (S2),

- $\quad$ process-dependent solution principles via the keywords "process" and "solution principle" (S3)

- $\quad$ and process-dependent design criteria via the keywords " process", "design" and "criteria" (S4).

Table 1. Synonyms for the keywords "AM-conformity", "solution principle" and "criteria"

\begin{tabular}{|c|c|c|}
\hline \multicolumn{3}{|c|}{ Synonyms and alternative terms for the keyword ... } \\
\hline "solution principle" & "AM-conformity" & "criteria" \\
\hline $\begin{array}{l}\text { "solution idea" } \\
\text { (Kumke et al., 2016) }\end{array}$ & $\begin{array}{l}\text { "design for additive manufacturing" } \\
\text { (Thompson et al., 2016) }\end{array}$ & $\begin{array}{l}\text { restriction } \\
\text { (Leutenecker-Twelsiek et al., 2016) }\end{array}$ \\
\hline $\begin{array}{l}\text { "design principle" } \\
\text { (Perez et al., 2015) }\end{array}$ & $\begin{array}{l}\text { "suitable for additive manufacturing" } \\
\text { (Frandsen et al., 2019) }\end{array}$ & $\begin{array}{l}\text { limitation } \\
\text { (Leutenecker-Twelsiek et al., 2016) }\end{array}$ \\
\hline $\begin{array}{l}\text { "final product" } \\
\text { (Ahtiluoto et al., 2019) }\end{array}$ & $\begin{array}{l}\text { "AM-conformal" } \\
\text { (Kumke et al., 2016) }\end{array}$ & $\begin{array}{l}\text { recommendation } \\
\text { (Klahn et al., 2016) }\end{array}$ \\
\hline $\begin{array}{l}\text { "final part" } \\
\text { (Kumke et al., 2016) }\end{array}$ & $\begin{array}{l}\text { "AM-enabled" } \\
\text { (Maidin et al., 2012) }\end{array}$ & $\begin{array}{l}\text { consideration } \\
\text { (Salmi et al., 2018) }\end{array}$ \\
\hline $\begin{array}{l}\text { "spare part" } \\
\text { (Frandsen et al., 2019) }\end{array}$ & & $\begin{array}{l}\text { guideline } \\
\text { (Klahn et al., 2014) }\end{array}$ \\
\hline $\begin{array}{l}\text { "replacement part" } \\
\text { (Frandsen et al., 2019) }\end{array}$ & & $\begin{array}{l}\text { "parameter", "factor", "basis" } \\
\text { (own addition) }\end{array}$ \\
\hline
\end{tabular}

It should be mentioned that the research as described above was limited to the three AM processes FDM, SLM and SLS, which determine the keyword "process". For example, synonyms such as Fused Filament Fabrication (FFF), which is known as an alternative term for FDM, or Direct Metal Laser Sintering (DMLS) instead of SLM have been included and were derived from Adam (2015), Kumke (2018), Thompson (2016), VDI 3405 (2014) and Weiss (2019). Furthermore, the list of keywords was extended by synonyms in singular and plural form as well as reasonable alternatives, e.g. the term "design for 
selective laser melting" was derived from "design for additive manufacturing". In addition, terms were shortened, e.g. from "additive manufacturing conformal" to "AM-conformal".

An initial search indicated that there have only been a few publications that are covering the primary search strategy (S1). Therefore, its keywords were scanned throughout the publication. Additional search strategies were included to complement the findings (see S2 to S4). However, to achieve greater relevance, the remaining search strings were applied to the title only.

Finally, all search strings were used in four indexed, electronic literature databases: Science Direct, Web of Science, Engineering Village and ProQuest.

The research was carried out from July to August 2020 and produced numerous results spread across a wide range of areas. Setting filters reduced the hit count. The first step was to filter by conference contributions and journals that were published solely between 1980, when AM technologies where commercialized, and today. Further filters were set in a second step depending on the database. Only publications related to engineering design (mechanical engineering, aerospace, medical technology etc.) were included. Figure 1 (left) shows the hit count after applying these filters. Afterwards the title, keywords, and abstracts of the remaining 664 publications were reviewed according to the following:

- $\quad$ Relevance with respect to design in additive manufacturing

- References/information on technical/economic aspects of products developed for an AM-process

- References/information on the recommendations and restrictions for AM-conformal design
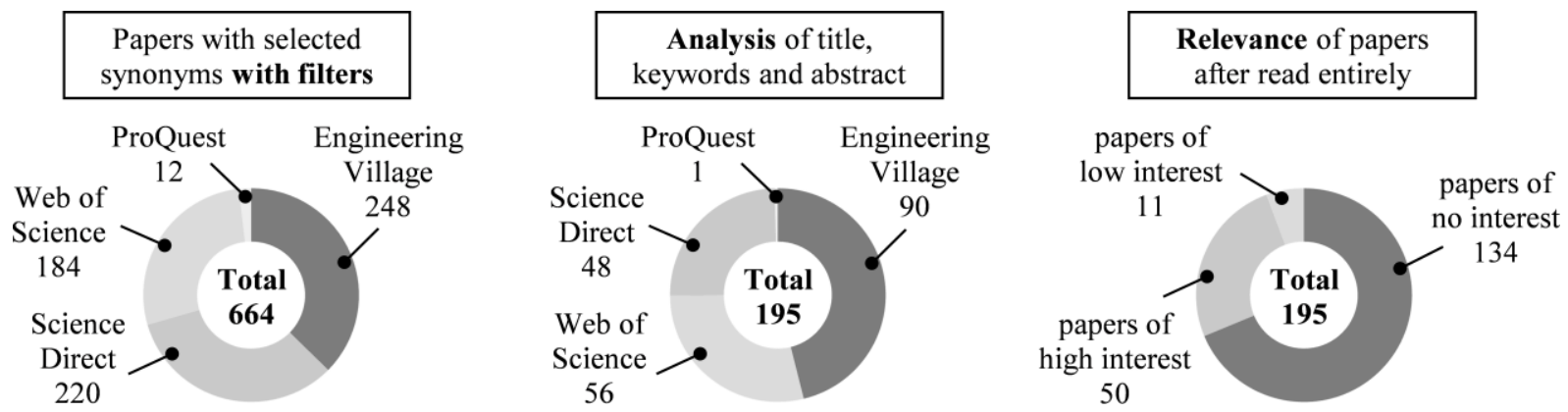

Figure 1. Papers with references to AM-conformity

After the initial analysis, 195 papers remained to be analyzed entirely according to their scope on criteria for the assessment of AM-conformity (see Figure 1, center). 8 papers were found on both Engineering Village and Science Direct, while 14 papers were found on both Engineering Village and Web of Science. Finally, all papers of high interest were further examined regarding to their relevance on solution principles (see Figure 1, right).

\section{CRITERIA FOR AM-CONFORMITY OF SOLUTION PRINCIPLES}

A total of 17 criteria were derived to assess the AM-conformity of solution principles (see Table 2). The findings from the preliminary analysis differ regarding their impact on DfAM. According to Kumke et al. (2016), a distinction is made between criteria in the "broad sense" and in the "strict sense" (see Table 2). On the one hand, the criteria in a strict sense refer to the actual design process and directly influence the design of a solution principle. On the other hand, the criteria in a broad sense exceed the boundaries of design and are related to the deliberate distinction from conventional or previously developed solutions. After all, they indirectly affect the design process. It must be mentioned that the following results refer to the manufacturing processes FDM, SLM and SLS. The criteria are valid for all three processes with one exception, which is noted in Table 2. In the following, the context of the criteria and their independencies is described only briefly. For greater clarity, the criteria in Table 2 are numerically coded and referenced in parentheses.

Essentially, a solution principle has to be designed for a previously defined AM-process, since the design capabilities, design guidelines, design and feature rules can be process-dependent $(1,2)$ (Leutenecker-Twelsiek, 2016). For example, smaller features that can be produced with SLM are not feasible with FDM, which is why adaptability to variable process parameters should be provided as well (3). 
Table 2. Set of criteria for AM-conformity of solutions principles

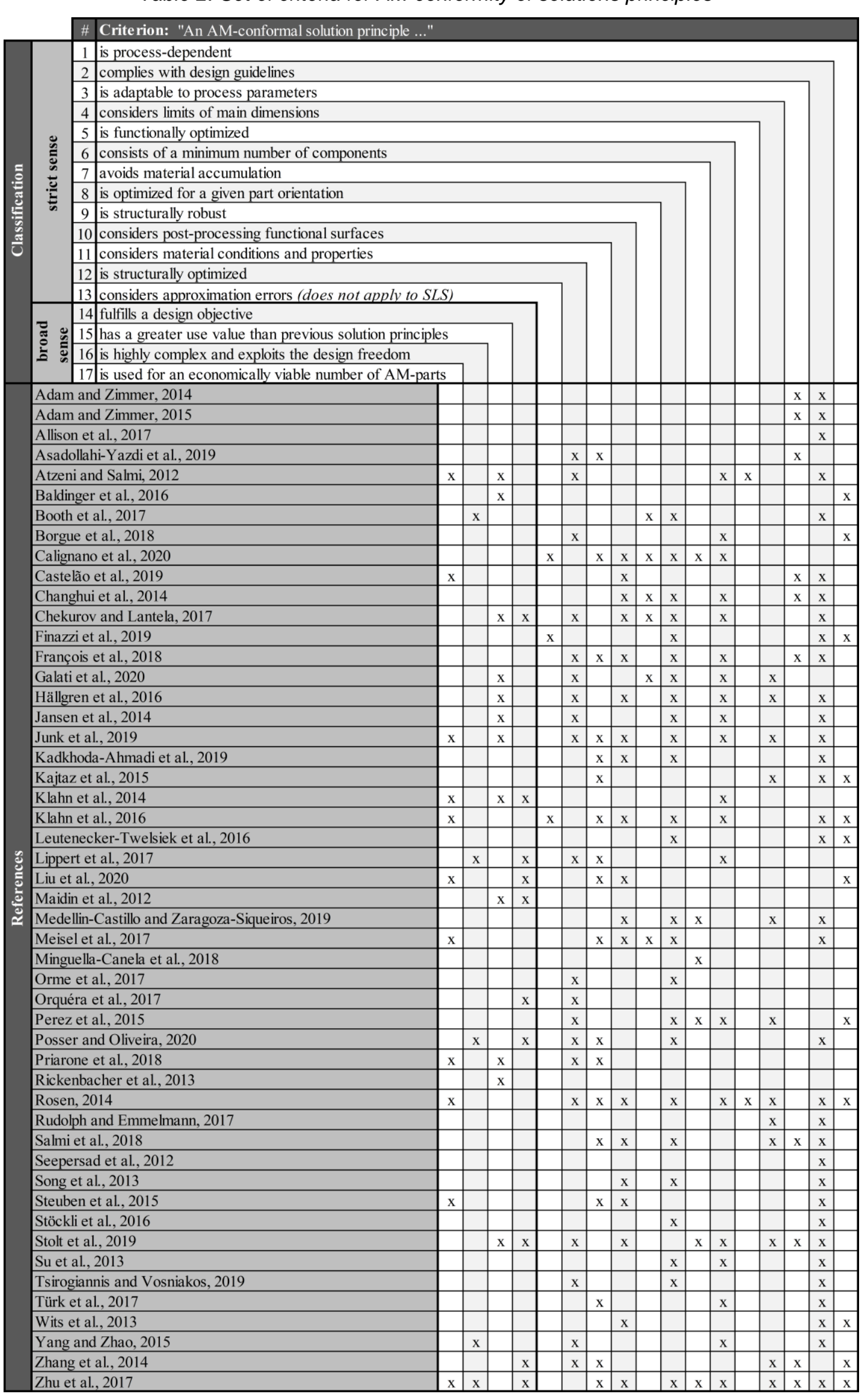


However, Adam and Zimmer (2015) argue, that there is a need for function and process-independent design rules. Furthermore, the feasible dimensions are determined by the process-dependent build size and the smallest feature size that can be manufactured due to the process parameters (4) (Zhu et al., 2017). Thus, Atzeni and Salmi (2012) suggest, that the function-dependent shape, and therefore the geometry, should be optimized in terms of functionality (5). In other words, the components of the same solution principle need to be consolidated. This can be achieved by means of functionally integration, which reduces the number of components needed to realize a solution principle (6) (Yang and Zhao, 2015). By rationalizing the components, a solution principle fulfills several functions inevitably. Additional functions can be implemented by adding features to the unused volume (Perez et al., 2015), which in return affects the function optimization positively. After consolidating geometries, it is important to ensure that no material accumulations arise in order to maintain the geometric accuracy and avoid geometrical distortion (7) (Stolt et al., 2019). In this context, part orientation is of particular importance. The design of the solution principle has to be linked to a part orientation by optimizing the functional surfaces and overhangs (8) (Meisel et al., 2017). In addition, the part orientation influences not only the mechanical properties (Meisel et al., 2017), but also the robustness (Chekurov and Lantela, 2017). Even under disadvantageous conditions (e.g. external stress) the solution principle should be dimensionally stable and reliable in its functionality (9).

François et al. (2018) explicitly refer to the post-processing of functional surfaces and recommend that they should be oriented in the same direction whenever possible. Since post-processing functional surfaces removes material, an excess of these surfaces is necessary to counteract the material removal and the resulting tolerance deviations (10). The material itself is usually determined after specifying the geometry of a solution principle. However, the material must be preselected, especially if materialrelated effects will be implemented. Furthermore, the choice of material has an impact on stability, design rules and anisotropic properties (11) (Klahn et al., 2016; Liu et al., 2020). Junk et al. (2019) and Lippert et al. (2017) suggest a lightweight conformal design. Thus, in terms of functionality, stability and weight, the shape and topology of the solution principle should be optimized structurally (12).

A rarely appearing criterion covers the approximation errors caused by the staircase effect, which can impact the surface quality of functional surfaces (Calignano et al., 2020). Since it only supports the manufacture of discrete values, possible approximation errors have to be considered in the design of solution principles (13) (Finazzi et al., 2019).

The criteria discussed above focus on technological aspects. On the contrary criteria in the broad sense focus more on the economic perspective. In addition to the compliance with a design goal (e.g. performance improvement or cost reduction) (14) (Rosen, 2014), the material and production costs, design effort and production time, as well as the preparation and post-processing have to be estimated in conceptual design (Liu et al., 2020). Thus, the solution principle must be more economical than another solution with the same use value (15) (Klahn et al., 2014). Simple geometries can be realized by conventional means that are more economical than additive manufacturing. Instead, the focus should be on complex geometries (16) (Kadkhoda-Ahmadi et al., 2019). Moreover, a redesigned solution principle, which is intended to replace a conventional solution, is primarily economical if the resulting part remains within the limited batch size of the selected AM-process (17) (Liu et al., 2020). With the literature analysis, not only criteria were derived, but also some of their mutual correlations (interdependencies) were identified. These correlations are summarized in a skew symmetric matrix in Table 3. In order to keep an appropriate framework, the interdependencies were only described in extracts above. We differ between four types of interdependencies (criterion A in row and criterion $\mathrm{B}$ in column): A influences B, B influences A, A and B influence each other and there is no correlation between A and B. Accordingly, 136 interdependencies are possible between the 17 listed criteria. 11 mutual and 59 unidirectional interdependencies were identified, leading to a total of 81 interdependencies, more than half of the possible mutual correlation. It is apparent that the criteria in the broad sense are strongly dependent on criteria in the narrow sense (see Table 3). In addition, process-dependency with eight, adaptability to process parameters and material consideration with nine correlations each influence most criteria. Hereby, the matrix represents the complexity in assessing solution principles by using criteria. If, for example, the solution principle is assessed negatively regarding process-dependency, retrospectively the compliance with design guidelines will be assessed negatively, as these are process-dependent (see Table 3). Thus, the mutual influences must be considered when assessing AM-conformity by interconnecting them. These interdependencies are particularly interesting when establishing strategies to achieve AM-conformity and should be further examined. 
Table 3. Interdependencies of criteria on AM-conformity of solution principles

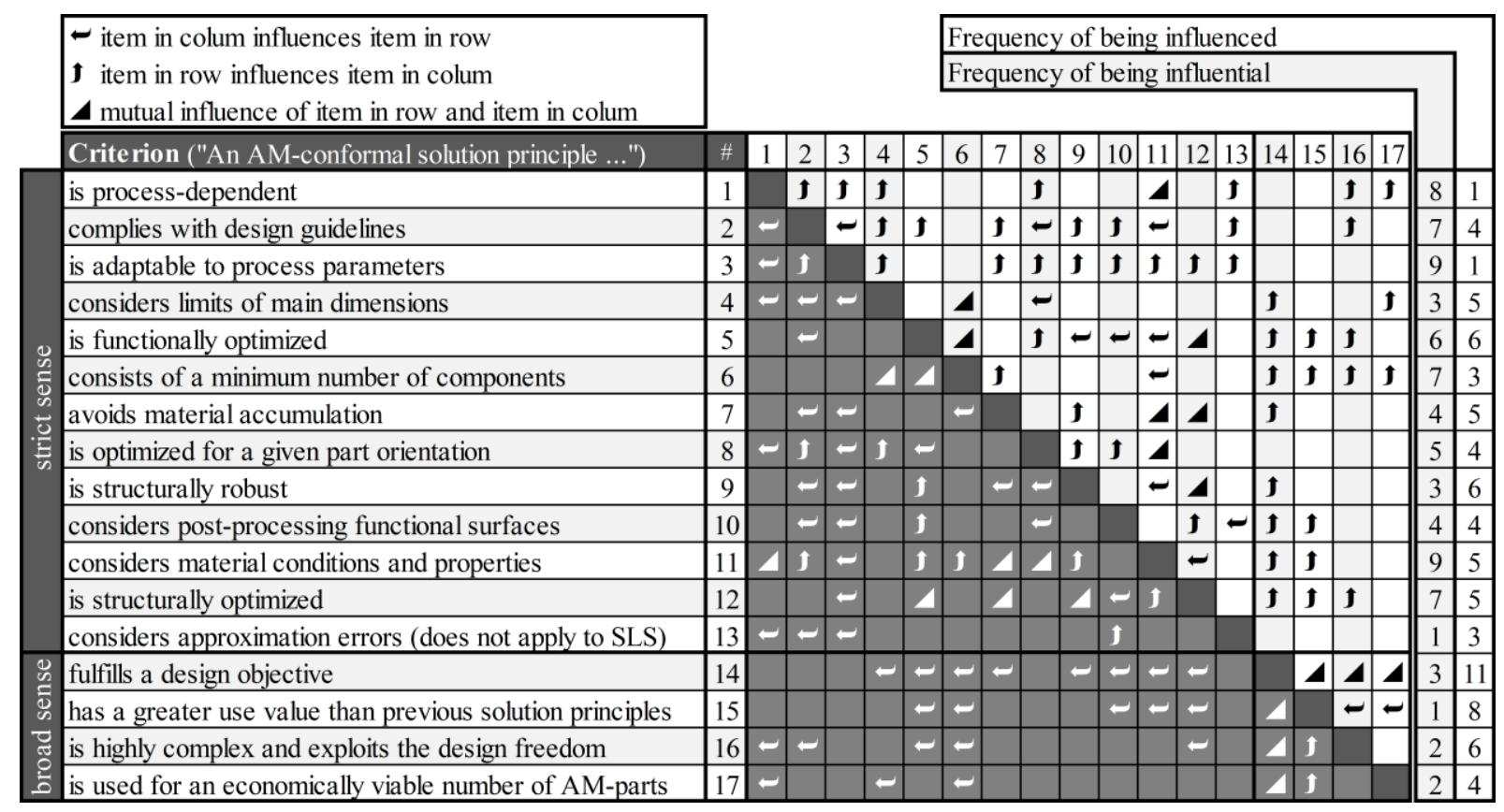

\section{CONCLUSION AND OUTLOOK}

The objective of this research was to develop criteria from a technological and economic perspective for the assessing of solution principles which are developed in the scope of Design for Additive Manufacturing in order to support designers in the conceptual design phase. Based on a systematic research and analysis of design for AM-methods as well as recommendations and restrictions for the design of additively manufactured products, retrospectively relevant indicators for the design of solution principles conformal for additive manufacturing were derived. Subsequently, criteria were defined on which future research can be based when assessing and collecting solution principles specifically developed for AM. Future research should evaluate the findings and thus, ensuring the development of methods for the assessment of solution principles tailored to the AM-processes.

Furthermore, the dependencies between the criteria were identified. It was found that the criteria frequently depend on each other. This suggests that a simple assessment of AM-conformity is complex and that a holistic view of the solution principles is necessary. Therefore, the correlations between the criteria need further investigation.

\section{REFERENCES}

Adam, G.A. (2015), Systematische Erarbeitung von Konstruktionsregeln für die additiven Fertigungsverfahren Lasersintern, Laserschmelzen und Fused Deposition Modeling, Shaker Verlag, Aachen.

Adam, G.A. and Zimmer, D. (2014), "Design for Additive Manufacturing - Element transitions and aggregated structures", Journal of Manufacturing Science and Technology, Vol. 7 No. 1, pp. 20-28. https://doi.org/10.1016/j.cirpj.2013.10.001.

Adam, G.A. and Zimmer, D. (2015), "On design for additive manufacturing: evaluating geometrical limitations", Rapid Prototyping Journal, Vol. 21 No. 6, pp. 662-670. https://doi.org/10.1108/RPJ-06-2013-0060.

Ahtiluoto, M., Ellman, A.U. and Coatanea, E. (2019), "Model for Evaluating Additive Manufacturing Feasibility in End-Use Production”, 22nd International Conference on Engineering Design (ICED19), Delft, Netherlands, August 5-8, 2019, pp. 799-808. https://doi.org/10.1017/dsi.2019.84.

Allison, J., Sharpe, C., Seepersad, C.C. and Kubiak, S. (2017), "Powder Bed Fusion Metrology for Additive Manufacturing Design Guidance”, 28th Annual International Solid Freeform Fabrication Symposium, Austin, TX, August 7-9, 2017, University of Texas, Austin, TX, pp. 2737-2756.

Asadollahi-Yazdi, E., Gardan, J. and Lafon, P. (2019), "Multi-objective optimization approach in design for additive manufacturing for fused deposition modeling”, Rapid Prototyping Journal, Vol. 25 No. 5, pp. 875-887. https://doi.org/10.1108/RPJ-07-2018-0186.

Atzeni, E. and Salmi, A. (2012), "Economics of additive manufacturing for end-usable metal parts", The International Journal of Advanced Manufacturing Technology, Vol. 62 No. 9-12, pp. 1147-1155. https://doi.org/10.1007/s00170-011-3878-1. 
Baldinger, M., Levy, G., Schönsleben, P. and Wandfluh, M. (2016), “Additive manufacturing cost estimation for buy scenarios", Rapid Prototyping Journal, Vol. 22 No. 6, pp. 871-877. https://doi.org/10.1108/RPJ-02-2015-0023.

Blessing, L.T. and Chakrabarti, A. (2009), DRM, a Design Research Methodology, Springer-Verlag, London. https://doi.org/10.1007/978-1-84882-587-1.

Booth, J.W., Alperovich, J., Chawla, P., Ma, J., Reid, T.N. and Ramani, K. (2017), "The Design for Additive Manufacturing Worksheet”, Journal of Mechanical Design, Vol. 139 No. 10, article number 100904. https://doi.org/10.1115/1.4037251.

Borgue, O., Müller, J., Panarotto, M. and Isaksson, O. (2018), "Function modelling and constraints replacement to support design for additive manufacturing of satellite components", NordDesign 2018, Linköping, Sweden, August 14-17, 2018.

Calignano, F., Iuliano, L., Galati, M., Minetola, P. and Marchiandi, G. (2020), “Accuracy of down-facing surfaces in complex internal channels produced by laser powder bed fusion (L-PBF)", 13th CIRP Conference on Intelligent Computation in Manufacturing Engineering (ICME '19), Gulf of Naples, Italy, July 17-19, 2019, Elsevier B.V., pp. 423-426. https://doi.org/10.1016/j.procir.2020.05.073.

Castelão, A., Soares, B., Machado, C.M., Leite, M. and Mourão, A. (2019), "Design for AM: Contributions from surface finish, part geometry and part positioning”, 29th CIRP Design Conference, Póvoa de Varzim, Portugal, May 8-10, 2019, Elsevier B.V., pp. 491-495. https://doi.org/10.1016/j.procir.2019.04.247.

Changhui, S., Yongqiang, Y., Zefeng, X., Di, W., Yang, L. and Ruicheng, L. (2014), "Design and direct manufacture of non-assembly abacus by Selective Laser Melting", International Symposium on Optoelectronic Technology and Application 2014, Beijing, China, March 13-15, 2014, SPIE, Washington, 929510. https://doi.org/10.1117/12.2072609.

Chekurov, S. and Lantela, T. (2017), "Selective Laser Melted Digital Hydraulic Valve System", $3 D$ Printing and Additive Manufacturing, Vol. 4 No. 4, pp. 215-221. https://doi.org/10.1089/3dp.2017.0014.

Finazzi, V., Demir, A.G., Biffi, C.A., Chiastra, C., Migliavacca, F., Petrini, L. and Previtali, B. (2019), "Design Rules for Producing Cardiovascular Stents by Selective Laser Melting: Geometrical Constraints and Opportunities", International Conference on Stents (ICS3M 2019), London, July 15-17, 2019, Elsevier B.V., pp. 16-23. https://doi.org/10.1016/j.prostr.2019.07.004.

François, M., Segonds, F., Rivette, M., Turpault, S. and Peyre, P. (2018), "Design for additive manufacturing (DfAM) methodologies: a proposal to foster the design of microwave waveguide components", Virtual and Physical Prototyping, Vol. 14 No. 2, pp. 175-187. https://doi.org/10.1080/17452759.2018.1549901.

Frandsen, C.S., Nielsen, M.M., Chaudhuri, A., Jayaram, J. and Govindan, K. (2020), "In search for classification and selection of spare parts suitable for additive manufacturing: a literature review", International Journal of Production Research, Vol. 58 No. 4, pp. 970-996. https://doi.org/10.1080/00207543.2019.1605226.

Galati, M., Calignano, F., Viccica, M. and Iuliano, L. (2020), “Additive Manufacturing Redesigning of Metallic Parts for High Precision Machines”, Crystals, Vol. 10 No. 3, article number 161. https://doi.org/10.3390/cryst10030161.

Gebhardt, A. (2012), Understanding additive manufacturing: Rapid prototyping, rapid tooling, rapid manufacturing, Hanser Publishers, Munich, Cincinnati. https://doi.org/10.3139/9783446431621.

Hällgren, S., Pejryd, L. and Ekengren, J. (2016), “(Re)Design for Additive Manufacturing”, 26th CIRP Design Conference, Stockholm, June 15-17, 2016, Elsevier Ltd., pp. 246-251. https://doi.org/10.1016/j.procir.2016.04.150.

Jansen, B., Doubrovski, E.L. and Verlinden, J.C. (2014), “Animaris Geneticus Parvus: Design of a complex multi-body walking mechanism: Design of a complex multi-body walking mechanism", Rapid Prototyping Journal, Vol. 20 No. 4, pp. 311-319. https://doi.org/10.1108/RPJ-10-2012-0087.

Junk, S., Klerch, B. and Hochberg, U. (2019), "Structural Optimization in Lightweight Design for Additive Manufacturing", 29th CIRP Design Conference, Póvoa de Varzim, Portugal, May 8-10, 2019, Elsevier B.V., pp. 277-282. https://doi.org/10.1016/j.procir.2019.04.277.

Kadkhoda-Ahmadi, S., Hassan, A. and Asadollahi-Yazdi, E. (2019), "Process and resource selection methodology in design for additive manufacturing", The International Journal of Advanced Manufacturing Technology, Vol. 104, pp. 2013-2029. https://doi.org/10.1007/s00170-019-03991-w.

Kajtaz, M., Witherow, B., Leary, M., Brandt, M. and Subic, A. (2015), "Design of a Personalised Faceguard for an Elite Cricketer", 1st International Design Technology Conference (DESTECH2015), Geelong, Australia, June-July, 2015, Elsevier Ltd., pp. 199-205. https://doi.org/10.1016/j.protcy.2015.07.032.

Klahn, C., Leutenecker, B. and Meboldt, M. (2014), "Design for Additive Manufacturing - Supporting the Substitution of Components in Series Products", 24th CIRP Design Conference, Milano, Italy, April 14-16, 2014, Elsevier B.V., pp. 138-143. https://doi.org/10.1016/j.procir.2014.03.145.

Klahn, C., Singer, D. and Meboldt, M. (2016), "Design Guidelines for Additive Manufactured Snap-Fit Joints", 26th CIRP Design Conference, Stockholm, June 15-17, 2016, Elsevier Ltd., pp. 264-269. https://doi.org/10.1016/j.procir.2016.04.130.

Kumke, M. (2018), Methodisches Konstruieren von additiv gefertigten Bauteilen, Springer-Verlag, Wiesbaden. https://doi.org/10.1007/978-3-658-22209-3. 
Kumke, M., Watschke, H. and Vietor, T. (2016), “A new methodological framework for design for additive manufacturing”, Virtual and Physical Prototyping, Vol. 11 No. 1, pp. 3-19. https://doi.org/10.1080/17452759.2016.1139377.

Laverne, F., Segonds, F., Anwer, N. and Le Coq, M. (2014), "DFAM in the design process: A proposal of classification to foster early design stages", CONFERE, Sibenik, Croatia, Juli 3-4, 2014.

Laverne, F., Segonds, F., Anwer, N. and Le Coq, M. (2015), "Assembly Based Methods to Support Product Innovation in Design for Additive Manufacturing: An Exploratory Case Study”, Journal of Mechanical Design, Vol. 137 No. 12, article number 121701. https://doi.org/10.1115/1.4031589.

Leutenecker-Twelsiek, B., Klahn, C. and Meboldt, M. (2016), “Considering Part Orientation in Design for Additive Manufacturing”, 26th CIRP Design Conference, Stockholm, June 15-17, 2016, Elsevier Ltd., pp. 408-413. https://doi.org/10.1016/j.procir.2016.05.016.

Lippert, B., Leuteritz, G. and Lachmayer, R. (2017), “An Approach to Implement Design for Additive Manufacturing in Engineering Studies”, 21 st International Conference on Engineering Design, Vancouver, August 21-25, 2017, pp. 51-60.

Liu, W., Zhu, Z. and Ye, S. (2020), “A Decision-making Methodology Integrated in Product Design for Additive Manufacturing Process Selection”, Rapid Prototyping Journal, Vol. 26 No. 5, pp. 895-909. https://doi.org/10.1108/RPJ-06-2019-0174.

Maidin, S.B., Campbell, I. and Pei, E. (2012), "Development of a design feature database to support design for additive manufacturing”, Assembly Automation, Vol. 32 No. 3, pp. 235-244. https://doi.org/10.1108/01445151211244375.

Medellin-Castillo, H.I. and Zaragoza-Siqueiros, J. (2019), "Design and Manufacturing Strategies for Fused Deposition Modelling in Additive Manufacturing: A Review", Chinese Journal of Mechanical Engineering, Vol. 32, article number 53. https://doi.org/10.1186/s10033-019-0368-0.

Meisel, N.A., Woods, M.R., Simpson, T.W. and Dickman, C.J. (2017), "Redesigning a Reaction Control Thruster for Metal-Based Additive Manufacturing: A Case Study in Design for Additive Manufacturing", Journal of Mechanical Design, Vol. 139 No. 10, article number 100903. https://doi.org/10.1115/1.4037250.

Minguella-Canela, J., Morales Planas, S., Gomà Ayats, J.R. and Los Santos López, M.A. de (2018), "Assessment of the Potential Economic Impact of the Use of AM Technologies in the Cost Levels of Manufacturing and Stocking of Spare Part Products”, Materials, Vol. 11 No. 8, article number 1429. https://doi.org/10.3390/ma11081429.

Orme, M.E., Gschweitl, M., Ferrari, M., Madera, I. and Mouriaux, F. (2017), "Designing for Additive Manufacturing: Lightweighting Through Topology Optimization Enables Lunar Spacecraft", Journal of Mechanical Design, Vol. 139 No. 10, https://doi.org/10.1115/1.4037304.

Orquéra, M., Campocasso, S. and Millet, D. (2017), "Design for additive manufacturing method for a mechanical system downsizing”, 27th CIRP Design Conference, Cranfield University, UK, May 10-12, 2017, Elsevier B.V., pp. 223-228. https://doi.org/10.1016/j.procir.2017.02.011.

Pahl, G., Beitz, W., Feldhusen, J. and Grote, K.-H. (2007), Engineering Design: A Systematic Approach, Springer-Verlag, London. https://doi.org/10.1007/978-1-84628-319-2.

Perez, K.B., Anderson, D.S., Holtta-Otto, K. and Wood, K.L. (2015), “Crowdsourced Design Principles for Leveraging the Capabilities of Additive Manufacturing", 20th International Conference on Engineering Design (ICED 15), Milan, July 27-30, 2015, Design Society, Glasgow, pp. 291-300.

Posser, T. and Oliveira, B.F., de (2020), "Design for additive manufacturing applied for mass reduction of a twostroke engine cylinder for portable machine”, International Journal on Interactive Design and Manufacturing, Vol. 14 No. 2, pp. 709-717. https://doi.org/10.1007/s12008-019-00596-1.

Pradel, P., Zhu, Z., Bibb, R. and Moultrie, J. (2018), "Investigation of design for additive manufacturing in professional design practice”, Journal of Engineering Design, Vol. 29 No. 4-5, pp. 165-200. https://doi.org/10.1080/09544828.2018.1454589.

Priarone, P.C., Ingarao, G., Lunetto, V., Di Lorenzo, R. and Settineri, L. (2018), "The role of re-design for Additive Manufacturing on the process environmental performance", 25th CIRP Life Cycle Engineering Conference (LCE), Copenhagen, April 30-March 2, 2018, Elsevier B.V., 124-129. https://doi.org/10.1016/j.procir.2017.11.047.

Rickenbacher, L., Spierings, A. and Wegener, K. (2013), “An integrated cost-model for selective laser melting (SLM)", Rapid Prototyping Journal, Vol. 19 No. 3, pp. 208-214. https://doi.org/10.1108/13552541311312201.

Rosen, D.W. (2007), “Computer-Aided Design for Additive Manufacturing of Cellular Structures”, ComputerAided Design and Applications, Vol. 4 No. 5, pp. 585-594. https://doi.org/10.1080/16864360.2007.10738493.

Rosen, D.W. (2014), "Research supporting principles for design for additive manufacturing", Virtual and Physical Prototyping, Vol. 9 No. 4, pp. 225-232. https://doi.org/10.1080/17452759.2014.951530.

Rudolph, J.-P. and Emmelmann, C. (2017), "Analysis of Design Guidelines for Automated Order Acceptance in Additive Manufacturing”, 27th CIRP Design Conference, Cranfield University, UK, May 12-12, 2017, Elsevier B.V., pp. 187-192. https://doi.org/10.1016/j.procir.2017.01.027. 
Salmi, A., Calignano, F., Galati, M. and Atzeni, E. (2018), “An integrated design methodology for components produced by laser powder bed fusion (L-PBF) process", Virtual and Physical Prototyping, Vol. 13 No. 3 , pp. 191-202. https://doi.org/10.1080/17452759.2018.1442229.

Seepersad, C.C., Govett, T., Kim, K., Lundin, M. and Pinero, D. (2012), “A Designer's Guide for Dimensioning and Tolerancing SLS Parts", 23rd Annual International Solid Freeform Fabrication Symposium, Austin, TX, August 6-8, 2012, University of Texas, Austin, TX, pp. 921-931.

Song, C., Yang, Y., Ye, Z. and Di Wang (2013), "Digital design and direct manufacturing of non-assembly mechanisms by selective laser melting", International Symposium on Assembly and Manufacturing (ISAM 2013), Xi'an, China, July 30-August 2, 2013, pp. 142-144. https://doi.org/10.1109/ISAM.2013.6643511.

Steuben, J., van Bossuyt, D.L. and Turner, C. (2015), "Design for Fused Filament Fabrication Additive Manufacturing", International Design Engineering Technical Conferences \& Computers and Information in Engineering Conference (IDETC/CIE2015), Boston, MA, August 2-5, 2015, ASME, New York.https://doi.org/10.1115/DETC2015-46355.

Stöckli, F.R., Modica, F. and Shea, K. (2016), "Designing passive dynamic walking robots for additive manufacture”, Rapid Prototyping Journal, Vol. 22 No. 5, pp. 842-847. https://doi.org/10.1108/RPJ-11-2015-0170.

Stolt, R., Elgh, F. and Heikkinen, T. (2019), "Design and Evaluation of Aerospace Components for SLM", 26th International Conference on Transdisciplinary Engineering (TE2019), Tokyo, Japan, July 30 - August 1, 2019, IOS Press BV, Amsterdam, Netherlands, pp. 157-166. https://doi.org/10.3233/ATDE190119.

Su, X., Yang, Y., Di Wang and Chen, Y. (2013), "Digital assembly and direct fabrication of mechanism based on selective laser melting”, Rapid Prototyping Journal, Vol. 19 No. 3, pp. 166-172. https://doi.org/10.1108/13552541311312157.

Thompson, M.K., Moroni, G., Vaneker, T., Fadel, G., Campbell, R.I., Gibson, I., Bernard, A., Schulz, J., Graf, P., Ahuja, B. and Martina, F. (2016), "Design for Additive Manufacturing: Trends, opportunities, considerations, and constraints”, CIRP Annals - Manufacturing Technology, Vol. 65 No. 2, pp. 737-760. https://doi.org/10.1016/j.cirp.2016.05.004.

Tsirogiannis, E. and Vosniakos, G.-C. (2019), "Redesign and Topology Optimization of an Industrial Robot Link for Additive Manufacturing”, Facta Universitatis - Mechanical Engineering, Vol. 17 No. 3, pp. 415-424. https://doi.org/10.22190/FUME181219003T.

Türk, D.-A., Kussmaul, R., Zogg, M., Klahn, C., Leutenecker-Twelsiek, B. and Meboldt, M. (2017), "Composites Part Production with Additive Manufacturing Technologies", 1st CIRP Conference on Composite Materials Parts Manufacturing (CIRP CCMPM 2017), Karlsruhe, Germany, June 8-9, 2017, Elsevier B.V., Amsterdam, pp. 306-311. https://doi.org/10.1016/j.procir.2017.03.359.

Valjak, F. and Bojčetić, N. (2019), "Conception of Design Principles for Additive Manufacturing”, 22nd International Conference on Engineering Design (ICED19), Delft, Netherlands, August 5-8, 2019, pp. 689-698. https://doi.org/10.1017/dsi.2019.73.

Verein Deutscher Ingenieure (1993), Systematic approach to the development and design of technical systems and products, VDI 2221:1993, Beuth Verlag, Berlin.

Verein Deutscher Ingenieure (2014), Additive manufacturing processes, rapid manufacturing: Basics, definitions, processes, VDI 3405:2014, Beuth Verlag, Berlin.

Watschke, H., Kuschmitz, S., Heubach, J., Lehne, G. and Vietor, T. (2019), “A Methodical Approach to Support Conceptual Design for Multi-Material Additive Manufacturing", 22nd International Conference on Engineering Design (ICED19), Delft, Netherlands, August 5-8, 2019, pp. 659-668. https://doi.org/10.1017/dsi.2019.70.

Weiss, F. (2019), Untersuchung des Entwicklungsprozesses für additiv gefertigte Bauteile mittels Bereitstellung einer elementaren Informationsstruktur, Dissertation, University of Stuttgart, Stuttgart.

Wits, W.W., Weitkamp, S.J. and Es, J. van (2013), "Metal additive manufacturing of a high-pressure micropump", 46th CIRP Conference on Manufacturing Systems (CIRP CMS 2013), Setúbal, Portugal, May 29-30, 2013, Elsevier B.V., Amsterdam, Netherlands, pp. 252-257. https://doi.org/10.1016/j.procir.2013.05.043.

Yang, S. and Zhao, Y.F. (2015), “Additive manufacturing-enabled design theory and methodology: a critical review”, The International Journal of Advanced Manufacturing Technology, Vol. 80, pp. 327-342. https://doi.org/10.1007/s00170-015-6994-5.

Zhang, Y., Bernard, A., Gupta, R.K. and Harik, R. (2014), "Evaluating the Design for Additive Manufacturing: A Process Planning Perspective”, 24th CIRP Design Conference, Milano, April 14-16, 2014, Elsevier B.V., pp. 144-150. https://doi.org/10.1016/j.procir.2014.03.179.

Zhu, Z., Pradel, P., Bibb, R. and Moultrie, J. (2017), “A Framework for Designing End Use Products for Direct Manufacturing Using Additive Manufacturing Technologies", 21 st International Conference on Engineering Design, Vancouver, August 21-25, 2017, pp. 327-336. 